\title{
O movimento LGBTI no Brasil, reflexões prospectivas
}

\author{
The LGBTI Movement in Brazil, prospective considerations \\ El movimiento LGBTI en Brasil, reflexiones prospectivas
}

\author{
Sérgio Luis Carrara ${ }^{1, a}$ \\ scarrara1@gmail.com | http://orcid.org/0000-0001-5165-3720 \\ ${ }^{1}$ Universidade Estadual do Rio de Janeiro, Instituto de Medicina Social. Rio de Janeiro, RJ, Brasil. \\ a Doutorado em Antropologia Social pela Universidade Federal do Rio de Janeiro.
}

\section{Resumo}

Esta nota busca contribuir para uma melhor compreensão do atual cenário político brasileiro que, em relação à diversidade sexual e de gênero, aparece marcado pelo paroxismo, pela polarização e por visíveis contradições. Nele, os diferentes poderes da República mostram tomar direções opostas. Simultaneamente, percebe-se uma sensível dessintonia entre o mundo social, no qual o respeito a tal diversidade parece cada vez mais incorporado à vida cotidiana, e os discursos conservadores que se articulam nos púlpitos e nos palanques. Como em outros importantes temas, o mundo contemporâneo parece dilacerado.

Palavras-chave: Política sexual; Ativismo LGBTI; Diversidade; Gênero; Sexualidade.

\begin{abstract}
This conjunctural note searches to contribute to a better knowledge of the current Brazilian political scene, characterized by a paroxysm, a polarization and perceptible contradictions when the subject is sexual and gender diversity. In this context, the different Republic forces show that their ways are in opposite directions. At the same time, we can observe a sensible lack of harmony between the social world, in which the respect for such diversity seems more and more incorporated into the population daily life, and the conservative discourses expressed in pulpits and joined up with those pronounced by politicians on their platforms. Like what happen to many other important themes, the contemporary world seems shattered.
\end{abstract}

Keywords: Sexuality policy; LGBTI activism; Diversity; Gender; Sexuality. 


\section{Resumen}

Esta nota de coyuntura intenta contribuir a una mejor comprensión del escenario político brasileño actual que, al respecto a la diversidad sexual y de género, aparece marcado por el paroxismo, por la polarización y por visibles contradicciones. En este contexto, los diferentes poderes de la República muestran seguir direcciones opuestas. Al mismo tiempo, es posible percibir una sensible desarmonía entre el mundo social en el que el respecto a tal diversidad parece cada vez más incorporado a la vida diaria, y los discursos conservadores se articulan en los púlpitos y en las tribunas. De la misma forma que ocurre en otros temas importantes, el mundo contemporáneo parece lacerado.

Palabras clave: Política sexual; Activismo LGBTI; Diversidad; Género; Sexualidad.

Este artigo faz parte do dossiê $\mathbf{4 0}$ anos do movimento LGBT: visibilidades e representações.

Contribuição dos autores: o autor é responsável por todo o texto.

Declaração de conflito de interesses: não há.

Fontes de financiamento: Conselho Nacional de Desenvolvimento Científico e Tecnológico.

Considerações éticas: não há.

Agradecimentos/Contribuições adicionais: não há.

Histórico do artigo: submetido: 10 ago. 2019 | aceito: 12 ago. 2019 | publicado: 12 set. 2019.

Apresentação anterior: não houve.

Licença CC BY-NC atribuição não comercial. Com essa licença é permitido acessar, baixar (download), copiar, imprimir, compartilhar, reutilizar e distribuir os artigos, desde que para uso não comercial e com a citação da fonte, conferindo os devidos créditos de autoria e menção à Reciis. Nesses casos, nenhuma permissão é necessária por parte dos autores ou dos editores. 
Durante 2018 e 2019, uma série de eventos e manifestações, da qual o lançamento do presente número da Reciis faz parte, tem comemorado o aniversário do movimento que, nascido Movimento Homossexual ou Movimento, vem sendo atualmente designado de Movimento LGBT, LGBTI, LGBTI+, ou ainda LGBTQI. Comemoram-se os 40 anos do movimento brasileiro e os 50 anos do movimento internacional. As comemorações internacionais celebram a reação ocorrida em 1969 contra a repressão policial que atingia zonas e lugares de sociabilidade em Nova York, e que ficaria conhecida como Rebelião de Stonewall, em homenagem ao bar no qual ela se organizou. No Brasil, os 40 anos contam-se a partir do surgimento em 1978, na cidade de São Paulo, do Somos (Grupo de Afirmação Homossexual), que inicia entre nós a luta contra o preconceito e a discriminação baseados na orientação sexual e na identidade ou expressão de gênero ${ }^{1-8}$.

Como outros eventos do mesmo tipo, tais efemérides são frutos de escolhas e convenções sociais. No nosso caso, de convenções que definem, por exemplo, o que deve ou não ser considerado 'político'. É certo que, antes da emergência do Somos e de organizações congêneres que lhe foram contemporâneas, havia outros grupos que reuniam 'homossexuais' e alguns deles sobreviveriam até hoje, como a famosa Turma OK, no Rio de Janeiro ${ }^{9-11}$. Mas tais grupos não são convencionalmente considerados como 'políticos'. Também não são assim percebidas as mobilizações 'culturais' e 'artísticas' imediatamente anteriores ao surgimento do Somos e que também colocavam em discussão a discriminação e o preconceito. Bons exemplos disso são, de um lado, o jornal O Lampião da Esquina, que surge em 1978, e, antes dele, do irreverente grupo teatral Dzi Croquettes, cujos espetáculos sacudiram a cena contracultural das grandes cidades brasileiras entre 1972 e $1976^{12}$.

Semessecontextodeinquietaçãocultural eartística, quemarcouopós-guerraemdiferentespaíses ocidentais, dificilmente seria possível compreender o surgimento de um movimento homossexual organizado que, em seus primeiros anos, contou, além do Somos, com organizações como Outra Coisa - Ação Homossexualista, Galf (Grupo de Ação Lésbico-Feminista), em São Paulo; Gatho (Grupo de Atuação Homossexual), em Olinda; Somos/RJ, Auê - Pela Livre Opção Sexual, Grupo Atobá de Emancipação Homossexual e Triângulo Rosa, no Rio de Janeiro; Grupo da Bahia, em Salvador; Beijo Livre, em Brasília. Todos esses grupos foram criados nos anos 1980. Como bem ressaltam historiadores e cientistas sociais que se ocuparam da questão no Brasil, a emergência do movimento tampouco pode ser compreendida fora do contexto da luta contra a ditadura e pela redemocratização do país. Como outros então chamados 'movimentos de minorias', como o movimento negro e o movimento feminista, o movimento homossexual brasileiro também se estrutura por meio do nem sempre fácil diálogo com as forças democráticas e de esquerda.

É no contexto de redemocratização do país que surge um movimento que deve ser considerado 'político' porque, desde logo, interpela o Estado e suas principais instituições, porque, desde o início, reivindica 'direitos'. O ponto central era a defesa do direito de não ser discriminado ou, dito de modo ligeiramente diferente, do direito de ser reconhecido e respeitado em sua diferença. Nesse sentido, é muito significativo que as primeiras campanhas do movimento visassem à ciência, à justiça e às políticas públicas ou governamentais. Inicialmente, no caso dessas últimas, por meio da resistência contra a atuação repressiva das forças policiais.

Em relação à ciência, o movimento articulou-se em seus primeiros anos contra a patologização da homossexualidade que, na figura do 'homossexualismo' - código 302.0 da Classificação Internacional de Doenças (CID) então vigente -, aparecia como um 'transtorno sexual'. Por meio de uma bem sucedida campanha que, liderada pelo Grupo Gay da Bahia, mobilizou políticos, cientistas e jornalistas, o Conselho Federal de Medicina suspenderia a aplicação desse código no Brasil em 1985. A atuação do movimento junto a diferentes associações científicas, como a Associação Brasileira de Antropologia e a Associação Brasileira de Estudos Populacionais, teve início já em 1980, na $32^{\text {a }}$ Reunião da Sociedade Brasileira para o Progresso da Ciência (SBPC), realizada na Universidade do Estado do Rio de Janeiro (Uerj). Nela, liderado pelo grupo Auê, o movimento promove um debate fora da programação oficial, intitulado "Homossexualismo, Repressão e Ciência”. O grupo abriu as discussões, que aconteceram no hall dos elevadores do nono andar 
da universidade (Campus Maracanã), anunciando: "O mais novo personagem a adentrar no cenário político brasileiro é o movimento homossexual, perfilando-se, ainda que talvez sem tarimba de quem já está nesse espetáculo há mais tempo, com as mulheres e os negros, no coro das chamadas 'minorias'."13

No mesmo contexto, o Grupo Gay da Bahia lança uma carta aberta "aos cientistas, universitários e à população em geral" em que afirma: "Vivemos atualmente sob o signo da ciência; os juízos de valor, as pré-noções, o dogmatismo são coisas do passado. A pesquisa empírica, a indução, a Universidade, o computador, a SBPC são conquistas definitivas na história da humanidade. Somos pela ciência livre e dialética no que ela representa de desmascaramento da ilusão, da mentira, no que ela significa questionamento do imutável, do sobrenatural. Somos pela ciência engajada no bem-estar da humanidade, pela ciência revertendo na melhoria das condições de vida do povo, pela ciência sabedoria que tem como objetivo principal a felicidade do homem em harmonia com a natureza. Somos contra a ciência dominada pelos interesses das classes dominantes, sejam estas classes econômicas, políticas, sexuais, raciais, culturais." ${ }^{14}$

A importância estratégica do engajamento contra a atribuição de caráter patológico à homossexualidade era bastante clara para os primeiros militantes, como expõe em uma carta João Antônio Mascarenhas, fundador do grupo Triângulo Rosa ${ }^{15} \mathrm{e}$ um de seus mais importantes expoentes do movimento: "O §302.0, mesmo quando não é citado, está na raiz de todos os dispositivos discriminatórios legais em relação à homossexualidade, dispositivos esses, que reforçam os preconceitos sociais vigentes. Se ele não existisse, que base jurídica haveria para fundamentar o preconceito contra a homossexualidade?"16

Em 1985, como já mencionado, o Conselho Federal de Medicina, suspenderia a necessidade de uso do código 302.0 no Brasil em casos envolvendo a homossexualidade de pacientes, colocando em questão seu suposto caráter patológico. Cinco anos depois, a Organização Mundial da Saúde (OMS) retiraria definitivamente a homossexualidade da CID. A orientação homossexual deixava de ser oficialmente considerada uma doença ou distúrbio no âmbito da medicina, embasando posteriormente a Resolução 1/1999 do Conselho Federal de Psicologia, que considera antiéticas as chamadas 'terapias de reversão', através das quais procura-se 'converter' homossexuais em heterossexuais.

Embora o movimento tenha sido exitoso em sua interpelação à ciência, esse sucesso não amparou (ao menos não tão rapidamente quanto parecia esperar João Antônio Mascarenhas) a interpelação que o movimento dirigia à justiça. Apesar do grande esforço do movimento nos anos que precederam a sua promulgação em 1988, a nova Constituição brasileira não incluiu a 'orientação sexual' entre os atributos pessoais (como raça, sexo, religião etc.) que não poderiam motivar atos discriminatórios ${ }^{17}$. Esse fracasso fez com que se passassem décadas até que tivéssemos no país qualquer reconhecimento dos direitos das pessoas LGBT. Em um contexto de ativismo e de visibilidade com o qual talvez nem sonhassem os primeiros militantes, tal reconhecimento viria não através do Congresso Nacional, que desde a Constituição de 1988 se mantém em silêncio sobre o tema, mas de ações apresentadas junto ao Supremo Tribunal Federal (STF).

Em 2011, no julgamento da Ação Direta de Inconstitucionalidade (ADI) 4277 e da Arguição de Descumprimento de Preceito Fundamental (ADPF) 132, o STF estenderia às relações conjugais entre pessoas do mesmo sexo os mesmos direitos (e deveres) reconhecidos para as relações conjugais heterossexuais. Em 2018, no julgamento da ADI 4275, o STF reconheceria o direito à autodeterminação relativa ao gênero, ou seja, a possibilidade de alterar nome e estado sexual nos registros civis, independentemente de processo judicial ou intervenção cirúrgica. E, finalmente, em 2019, ou seja, quase meio século depois do surgimento do ativismo LGBTI no país, o STF equipararia legalmente a discriminação baseada em orientação sexual e identidade de gênero (a homofobia e a transfobia) ao crime de racismo mediante o julgamento da Ação Direta de Inconstitucionalidade por Omissão (ADO) 26 e do Mandado de Injunção (MI) 4733.

Em relação às políticas governamentais, a atuação do movimento tem início com a crítica à intervenção abusiva da polícia, ou seja, com a denúncia da violência de Estado que frequentemente atingia a população LGBTI. A campanha contra a repressão policial marcaria a primeira aparição pública do movimento em uma passeata realizada, na cidade de São Paulo, em 14 de junho de 1980, para protestar contra as operações 
da polícia comandada então pelo delegado Wilson Richetti. Em operações de 'limpeza urbana', o delegado acionava a lei de contravenções penais de 1942 para prender, como 'vadios', gays, travestis e prostitutas que perambulavam pelas ruas do centro da cidade. Posteriormente, a reação a esse tipo de violência policial, que não podemos afirmar ter sido completamente extirpada do cenário em todo o Brasil, foi uma das bases para a organização do movimento brasileiro de travestis que, nos anos 1990, emerge já em contexto social marcado pela difusão da epidemia de HIV/aids ${ }^{18,19}$.

É na luta contra a epidemia de HIV/aids que, sobretudo a partir da segunda metade da década de 1990, o movimento se capilariza e que os grupos se multiplicam em um cenário marcado pela visibilidade massiva proporcionada pelas cada vez mais volumosas paradas de orgulho LGBT $^{20,21, \mathrm{i}}$. O ciclo de governos democráticos que se sucedem entre 1995 e 2016 marcaria o crescente envolvimento do movimento na construção de políticas públicas voltadas à população LGBTI nos mais diferentes setores, como saúde, segurança, educação e cultura. Como principais marcos desse processo, destacamos a aprovação, em 2004, no âmbito do Ministério da Saúde e do Conselho Nacional de Combate à Discriminação, do programa Brasil Sem Homofobia - Programa de Combate à Violência e à Discriminação contra GLTB e de Promoção da Cidadania Homossexual, e a implementação, a partir de 2008, sob a iniciativa da então Secretaria Especial de Direitos Humanos, do ciclo de conferências nacionais de políticas públicas voltadas para a população LGBT ${ }^{22,23}$. Ressaltamos que tais iniciativas se organizam sob a presidência de Luiz Inácio Lula da Silva, cujo comprometimento com a causa era destacado pelo movimento desde a sua inserção na arena política brasileira no início dos 1980.

Do ponto de vista das políticas governamentais, esse cenário favorável à pauta de reivindicações do movimento começa a se alterar drasticamente a partir de 2011, quando, pela pressão de forças políticas organizadas no Congresso em torno da chamada bancada evangélica, o governo de Dilma Rousseff suspende a distribuição do material didático intitulado 'Escola Sem Homofobia'. Seus detratores o alcunharam de 'kit gay' e sobre ele articularam um pânico moral segundo o qual o governo intentava (homos)sexualizar as crianças, destruir as famílias e fomentar a implantação do comunismo no país ${ }^{24}$. Um pouco mais tarde, a partir de 2014, com o arsenal retórico reforçado pela incorporação da expressão 'ideologia de gênero', as mesmas forças iriam voltar-se contra a diretriz incorporada aos planos de educação brasileiros que buscavam promover nas escolas públicas uma educação não sexista e anti-homofóbica. Podemos dizer que entre 2011 e 2014 organiza-se a mais eficiente reação contra o processo de luta por direitos inaugurado com o surgimento do movimento LGBTI no Brasil. E essa mesma pauta de reacionarismo moral marcou o discurso de campanha do candidato vitorioso nas últimas eleições presidenciais e tem singularizado sua atuação desde a posse, em 2019. No plano do Poder Executivo, assistimos hoje à rápida destruição do que se conseguiu nas últimas duas décadas. O universo da ciência e o da justiça são um pouco mais impermeáveis, mas encontram-se também, sobretudo o primeiro, sob fogo cerrado.

Podemos afirmar que o presente número da Reciis vem, assim, contribuir para que possamos compreender melhor um cenário político de paroxismo, de polarização e de visíveis contradições. Nele, os diferentes poderes da República tomam direções opostas. Além disso, nota-se sensível dessintonia entre o mundo social, no qual o respeito à diversidade sexual e de gênero parece cada vez mais incorporado à vida cotidiana, e os discursos conservadores que se articulam nos púlpitos e nos palanques. Como em outros importantes temas, o mundo contemporâneo mostra-se dilacerado. O momento é, portanto, oportuno para voltarmos sobre os passos de um movimento que ousou insurgir-se contra seculares processos de estigmatização e de desumanização, imaginando futuros alternativos, mais inclusivos e diversos. Esse parece ser o grande desafio da conjuntura brasileira atual, seja para militantes e políticos, seja para acadêmicos e juristas.

i O movimento não apenas se capilariza, mas também se diversifica, sendo a luta contra a epidemia também estratégica para a organização do movimento de lésbicas e mulheres bissexuais. 


\section{Referências}

1. Trevisan JS. Devassos no paraíso. São Paulo: Max Limonad; 1986.

2. MacRae EJBN. A construção da igualdade: política e identidade homossexual no Brasil da "abertura". Salvador: EDUFBA; 2018.

3. Facchini R. Sopa de Letrinhas? Movimento homossexual e produção de identidades coletivas nos anos 90. Rio de Janeiro: Garamond; 2005.

4. Facchini R. Múltiplas identidades, diferentes enquadramentos e visibilidades: um olhar para os 40 anos do movimento LGBTI. In: Green JN, Quinalha R, Caetano M, Fernandes M, organizadores. História do movimento LGBT no Brasil. São Paulo: Alameda; 2018. p. 311-30.

5. Simões JA, Facchini R. Na trilha do arco-íris: do movimento homossexual ao LGBT. São Paulo: Fundação Perseu Abramo; 2009.

6. Green JN. O Grupo SOMOS, a esquerda e a resistência à ditadura. In: Green J; Quinalha R., organizadores. Homossexualidade e a ditadura brasileira: opressão, resistência e a busca da verdade. São Carlos: Editora da Universidade Federal de São Carlos; 2014. p. 177-200.

7. Green JN, Quinalha R, Caetano M, Fernandes M, organizadores. História do movimento LGBT no Brasil. São Paulo: Alameda; 2018.

8. Câmara C. Um olhar sobre a história do ativismo LGBT no Rio de Janeiro. Revista do Arquivo Geral da Cidade do Rio de Janeiro. 2015;(9); 373-96.

9. Green JN. Além do carnaval: a homossexualidade masculina no Brasil do século XX. São Paulo: Unesp; 2000.

10. Soliva TB. A confraria gay: um estudo sobre a trajetória da Turma OK. In: Green JN, Quinalha R, Caetano M, Fernandes M, organizadores. História do movimento LGBT no Brasil. São Paulo: Alameda; 2018. p. 121-35.

11. Soliva TB. Sobre afetos e resistências: uma análise da trajetória da Turma OK (Rio de Janeiro, Brasil). Sex., Salud Soc. (Rio J). 2019;(31): 57-80. doi: http://dx.doi.org/10.1590/1984-6487.sess.2019.31.04.a.

12. Lobert R. A palavra mágica: a vida cotidiana do Dzi Croquettes. Campinas: Unicamp; 2010.

13. O movimento homossexual: uma luta libertária. São Paulo: Unicamp; 1980. Arquivo Edgard Leuenroth; Fundo Outra Coisa.

14. Carta Aberta do Grupo Gay da Bahia aos cientistas, universitários e à população em geral por ocasião da 32a Reunião Anual da S.B.P.C.. São Paulo: Unicamp; [Data desconhecida]. Arquivo Edgard Leuenroth; Fundo Triângulo Rosa.

15. Câmara C. 2002. Cidadania e orientação sexual: a trajetória do grupo Triângulo Rosa. Rio de Janeiro: Academia Avançada.

16. Carta de João Antônio Mascarenhas para a jornalista Miriam Macedo. Revista Visão; 198326 mar. São Paulo: Unicamp; 2003. Arquivo Edgard Leuenroth; Fundo Triângulo Rosa.

17. Carrara SL,Vianna ARB. 2008. Os direitos sexuais e reprodutivos no Brasil a partir da "Constituição Cidadã". In: Oliven R, Ridenti M, Brandâo G. organizadores. A Constituição de 1988 na vida brasileira. São Paulo: Aderaldo\&Rothschild; 2008; p. 334-59.

18. Carvalho M. Travesti, mulher transexual, homem trans e não binário: interseccionalidades de classe e geração na produção de identidades políticas. Cad Pagu. 2018;(52):e185211.

19. Carvalho M, Carrara S. Em direito a um futuro trans?: contribuição para a história do movimento de travestis e transexuais no Brasil. Sex., Salud Soc. (Rio J). 2013:(14); 319-51. doi: http://dx.doi. org/10.1590/S1984-64872013000200015.

20. Almeida GES. Movimento de lésbicas: mobilização e protagonismo. Democracia Viva. 2006:(32):54-6.

21. Almeida GS, Heilborn ML. Não somos mulheres gays: identidade lésbica na visão de ativistas brasileiras. Gênero. 2008:9(1):225-49.

22. Aguião S. Não somos um simples conjunto de letrinhas: disputas internas e (re)arranjos da política LGBT. Cad Pagu. 2016:(1):279-310. doi: http://dx.doi.org/10.1590/18094449201600460279. 
Reciis - Rev Eletron Comun Inf Inov Saúde. 2019 jul.-set.;13(3):450-6 | [www.reciis.icict.fiocruz.br] e-ISSN 1981-6278

23. Aguião S. Fazer-se no "Estado": uma etnografia sobre o processo de constituição dos "LGBT" como sujeitos de direitos no Brasil contemporâneo. Rio de Janeiro: Eduerj; 2018.

24. Vital C, Lopes PVL. Religião e política: uma análise da atuação de parlamentares evangélicos sobre direitos das mulheres e de LGBTs no Brasil. Rio de Janeiro: Fundação Heinrich Böll; 2013. 